\title{
Estudo Estratégico da Cadeia Produtiva da Indústria Cerâmica no Estado de São Paulo: Parte IV - Indústria de Louça e Porcelana (Mesa, Utilitários e Decoração), Demanda Mineral e Análise de Fatores de Competitividade Setorial
}

\author{
Marsis Cabral Junior ${ }^{\star *}$, Paulo Brito Moreira de Azevedo ${ }^{b}$, Gláucia Cuchierato ${ }^{c}$, José Francisco Marciano Motta ${ }^{\mathrm{d}}$ \\ ${ }^{a}$ Laboratório de Recursos Hídricos e Avaliação Geoambiental - LABGEO / Centro de Tecnologias Geoambientais / Instituto de \\ Pesquisas Tecnológicas do Estado de São Paulo - IPT \\ ${ }^{b}$ Coordenadoria de Planejamento e Negócios / Instituto de Pesquisas Tecnológicas do Estado de São Paulo - IPT \\ ${ }^{c}$ GeoAnsata Projetos e Serviços em Geologia \\ ${ }^{d}$ Consultor - Bolsista Fapesp \\ *e-mail:marsis@ipt.br
}

\begin{abstract}
RESUMO
Este trabalho deriva de estudo de maior abrangência dirigido à elaboração de um diagnóstico técnico-econômico da indústria cerâmica no estado de São Paulo, com vistas a subsidiar ações de governo que garantam o abastecimento sustentável de matérias-primas minerais a este setor da economia. Entre as cerâmicas tradicionais foram priorizados os segmentos industriais de maior relevância econômica no Estado e com consumo significativo de bens minerais, a saber: Cerâmica Vermelha, Revestimentos, Louça Sanitária, Louça e Porcelana - Mesa, Utilitários e Decoração, Colorifícios (Fritas, Esmaltes e Corantes), e Cerâmica Técnica - Isoladores Elétricos. Nesse contexto, as avaliações desses segmentos e a análise estratégica efetuadas buscaram estabelecer um arcabouço de informações, bem como sugestões de iniciativas para o fortalecimento do setor produtivo, que poderão auxiliar a formulação de políticas para modernização e aprimoramento do sistema de suprimento mineral ao parque cerâmico paulista. Os principais resultados desse estudo estão sendo apresentados em uma série de quatro artigos. Os três primeiros, já publicados, abordaram a contextualização e fatos motivadores do estudo, breve histórico e características gerais da indústria cerâmica no Estado, sendo tratados os segmentos de cerâmica vermelha, revestimentos, colorifícios, sanitários e cerâmica técnica. Neste quarto e último artigo da série é analisada a indústria de louça e porcelana - mesa, utilitários e decoração, bem como são apresentados um balanço do consumo e projeções de demanda mineral para o parque cerâmico paulista e uma análise estratégica da cadeia produtiva mínero-cerâmica.
\end{abstract}

Palavras-Chave: cerâmica; matérias-primas, indústria; mineração; tecnologia

\section{INTRODUÇÃO}

Este trabalho decorre de estudo desenvolvido pelo Instituto de Pesquisas Tecnológicas do Estado de São Paulo (IPT, 2018) e financiado pela Subsecretaria de Mineração da Secretaria de Energia e Mineração - SEM do Estado de São Paulo ${ }^{1}$, que envolveu a elaboração de um diagnóstico técnico-econômico da indústria cerâmica no Estado de São Paulo, com a finalidade de coletar subsídios que permitam orientar ações de governo que garantam o abastecimento sustentável de matérias-primas minerais necessárias a este setor da economia, a curto, médio e longo prazo.

Contido nesse escopo geral, o desenvolvimento do estudo contemplou as seguintes metas:

\footnotetext{
${ }^{1}$ Em 2019 com a reforma da estrutura administrativa do governo paulista, as atribuições da Subsecretaria de Mineração foram integradas a Coordenadoria de Petróleo, Gás e Mineração dentro da Secretaria Estadual de Infraestrutura e Meio Ambiente- SIMA.
}

a) caracterização qualitativa da estrutura de mercado e empresarial do elo central da cadeia produtiva cerâmica, isto é, do segmento de manufatura cerâmica, abrangendo os principais segmentos de manufatura cerâmica intensivos em consumo de minerais industriais, a saber: Cerâmica Vermelha, Revestimentos, Louça Sanitária, Louça e Porcelana de Mesa e Decorativa, Isoladores Elétricos e Colorifícios;

b) projeções de consumo de bens minerais: estimativa de crescimento do parque cerâmico e da demanda derivada de insumos minerais, circunstanciada em três cenários de crescimento (pessimista, neutro e otimista); e

c) avaliação estratégica do setor cerâmico: indicações conclusivas sobre os principais fatores que interferem na competitividade da indústria cerâmica paulista e sugestão de diretrizes e ações para o aprimoramento competitivo, mormente relacionadas à demanda de bens minerais. 
Os principais resultados desse estudo estão sendo apresentados em uma série de quatro artigos. Os três primeiros, já publicados, abordaram a contextualização e fatos motivadores do estudo, breve histórico e características gerais da indústria cerâmica no Estado, sendo tratados os segmentos de cerâmica vermelha, revestimentos, colorifícios, sanitários e cerâmica técnica (Cabral Junior et al., 2019a;b;c). Neste quarto e último artigo da série é analisada a indústria de louça e porcelana - mesa, utilitários e decoração, bem como são apresentados um balanço do consumo e projeções de demanda mineral para o parque cerâmico paulista e uma análise estratégica da cadeia produtiva mínero-cerâmica.

\section{INDÚSTRIA DE LOUÇAS E PORCELANA - MESA, UTILITÁRIA E DECORATIVA}

O segmento de louça de mesa inclui peças de porcelanas (corpo isento de absorção de água) ou louças e/ou faianças (produtos com certa absorção d'água), utilizados como utilitários no dia-a-dia do ambiente doméstico e em ambientes comerciais (hotéis e restaurantes). As porcelanas e louças apresentam uma diversidade de produtos. No uso residencial, destacam-se as linhas de mesa e aparelhos de jantar (tableware e dinnerware), que agrupam os jogos de pratos e outros utensílios de mesa, tais como jogos de café e chá, canecas, xícaras, tigelas, assadeiras. Dentre os produtos para o ambiente de hotéis e restaurantes, que compõe a linha hoteleira (hotelware), destacam-se principalmente os pratos e xícaras, e secundariamente, os demais objetos desse ambiente. Outra linha de produtos são as peças de ornamentação, a exemplo de vasos, estatuetas e outros itens decorativos e para presente, como porta-objetos, bibelôs, etc.

Até alguns anos atrás este segmento inseria-se no contexto do setor de cerâmica branca, o qual agrupava uma grande variedade de produtos, tais como louças e porcelanas (utilitárias e decorativas), sanitários e porcelana técnica. Este grupo de produtos está sendo denominado genericamente de porcelana e louça, mas, quanto à natureza do corpo cerâmico, pode ser definido como porcelana, grés e faiança. Estas denominações são baseadas na absorção d'água do corpo cerâmico (suporte e biscoito), como segue:

- Porcelana: quando a absorção é zero (pode-se admitir até $0,5 \%)$;

- Grés: são designados os materiais com baixíssima absorção (geralmente entre 0,5\% e 3\%);

- Faiança (ou louça): refere-se aos corpos mais porosos (geralmente superior a 3\%). No entanto, o estabelecimento de nomenclatura, bem como o desempenho dos produtos, ainda não está devidamente normalizado e é um dos pontos necessários para o controle de qualidade do segmento.

Na linha doméstica, a produção brasileira atende uma parte do mercado interno, sendo completado pela importação de produtos, sobretudo da China. Segundo alguns fabricantes, o Brasil não tem estrutura produtiva para atender todo o mercado doméstico, sendo necessária a importação. O principal destino da produção nacional é o Estado de São Paulo, contando com pequena parcela de exportação pelas empresas líderes do segmento.

\subsection{Estrutura Produtiva e Empresarial}

\subsubsection{Contexto brasileiro}

A primeira empresa de louça branca do Brasil foi a Fábrica de Louças Santa Catharina, fundada em 1913 pelo italiano Romeo Ranzini, no bairro da Água Branca, em São Paulo. Nos anos seguintes, muitos técnicos e operários especializados, vindos da Itália para trabalhar na fábrica, acabaram fundando outras empresas de louça branca na região próxima à Capital. Em 1928, o estado já contava com nove fábricas (cinco na cidade de São Paulo) e, em 1937, havia 18 delas (nove na Capital), que produziam aparelhos de jantar, pratos, travessas, xícaras, pires, tigelas, sopeiras e canecas (Bellingieri, 2003).

Os fatores determinantes para a instalação dessas empresas foram a disponibilidade de matérias-primas, tais como caulim, argila, feldspato e quartzo, com jazidas situadas próximas à cidade de São Paulo e a grande expansão do mercado consumidor paulista no período.

Conforme informações de representantes do Sindicato da Indústria da Cerâmica de Louça de Pó de Pedra, da Porcelana e da Louça de Barro no Estado de São Paulo Sindilouça, a falta de uma entidade nacional, bem como a enorme variedade de peças, em termos de tipo e tamanho, dificulta a quantificação da produção no segmento. No início dos anos 2000, a produção brasileira era estimada em torno de 200.000 milhões de peças/ano, o que representava $2 \%$ do montante mundial (Ruiz et al., 2011; IPT, 2006). Para esse patamar de produção foi considerado um consumo anual da ordem de 55.000 toneladas de matérias-primas (argilas, feldspato, filito, caulim, calcário e dolomito).

É certo que houve uma retração na produção nacional em relação aos valores apresentados para o início dos anos 2000, embora pelo menos parte do setor tenha retomado as suas vendas, notadamente a partir dos últimos cinco anos. A produção atual deve se situar em torno de 150.000 milhões de peças/ano, o que deve corresponder ao consumo anual de cerca de 40.000 toneladas de massa.

No setor predominam as pequenas empresas, embora existam também algumas de médio a grande porte, como a Cerâmica Oxford e a Porcelana Schmidt, empresas catarinenses que lideram a produção nacional em termos de quantidade e investimentos em tecnologia e design.

Na Tabela 1 estão relacionados os principais polos e empresas de porcelana e louça de mesa e decorativa do Brasil. Há poucas empresas de grande porte, com produção superior a 20 milhões de peças/ano, como Porcelana Schmidt e Oxford; uma dezena de empresas médias (produção de 1 a 10 milhões peças/ano - Porto Brasil, Scalla, Fiori, Geni, Estudio Tacto, Cerâmica Brasília, dentre outras); e mais de duas centenas de micro e pequenas empresas - MPEs (produção inferior a 1 milhão peças/ano), concentradas 
Tabela 1 - Principais polos e empresas brasileiras de porcelana e louça de mesa.

\begin{tabular}{|c|c|c|}
\hline Empresa ou Polo & Unidades Fabris/ Empresas & Principais Produtos \\
\hline \multirow{2}{*}{ Schmidt } & Pomerode (SC) & \multirow{2}{*}{ Porcelana de mesa } \\
\hline & Campo Largo (PR) & \\
\hline \multirow{2}{*}{ Oxford } & São Bento do Sul (SC) & \multirow{2}{*}{ Porcelana e louça de mesa } \\
\hline & São Mateus (ES) & \\
\hline \multirow{5}{*}{ Campo Largo - PR } & Studio Tacto & Louça de mesa \\
\hline & Germer & Porcelana hotelware \\
\hline & Cer. Brasília & Louça de mesa \\
\hline & Outras cerca de 30 & \multirow{2}{*}{ Louça de mesa } \\
\hline & indústrias & \\
\hline \multirow{3}{*}{ Porto Ferreira - SP } & Cer. Porto Brasil & Louça de mesa \\
\hline & Cer. Scalla & Louça de mesa e artigos decorativos \\
\hline & Cerca de 70 empresas (maior parte MPEs) & Artigos decorativos (louças de mesa) \\
\hline \multirow{2}{*}{ Pedreira - SP } & Porcelútil / Panger & $\begin{array}{l}\text { Porcelana e louça decorativa; porcelana e } \\
\text { louça de mesa }\end{array}$ \\
\hline & Cerca de 90 empresas (maior parte MPEs) & $\begin{array}{l}\text { Porcelana e louça decorativa; porcelana e } \\
\text { louça de mesa }\end{array}$ \\
\hline Monte Sião-Andradas- MG & Diversas MPEs & Louça decorativa e de mesa \\
\hline
\end{tabular}

Fonte: atualizado a partir de Ruiz et al. (2011); IPT (2006).

em Campo Largo (Paraná), Porto Ferreira e Pedreira (ambas em São Paulo).

Geograficamente, além de unidades isoladas situadas na Grande São Paulo, no interior catarinense, em Pomerode e São Bento do Sul, e em São Mateus no Espírito Santo, há quatro importantes aglomerados produtivos que concentram as MPEs. Esses importantes polos produtores estão localizados nos municípios paulistas de Pedreira e Porto Ferreira, Campo Largo no Paraná e Monte Sião Andradas em Minas Gerais. A única empresa de capital estrangeiro (portuguesa) é a Porcelana Verbano, instalada em Porto Ferreira.

Desde abertura comercial do início dos anos 1990, o segmento nacional de porcelana e louça vem sofrendo uma forte concorrência das cerâmicas chinesas. Os baixos preços dos produtos asiáticos afetaram fortemente a produção no país, não só inibindo as exportações, como também ganhando fatias expressivas do mercado doméstico brasileiro. Essa situação começou a se reverter de forma mais sustentada apenas a partir de 2013, quando os produtos de mesa tiveram proteção de legislação antidumping da Câmara de Comércio Exterior- Cacex (Resolução No 57, de 24 de julho de 2013). Essa legislação coibiu a importação e favoreceu as empresas brasileiras, que passaram para um novo período de expansão.

Alguns exemplos da difícil conjuntura vivenciada pelas empresas mediante o cenário de competição com os produtos chineses podem ser exemplificados por alguns casos: a Cerâmica Tirolesa em Campo Largo, que produzia cerca de 20 milhões peças/ano em 2010, fechou as portas antes da lei antidumping. Destino semelhante também ocorreu com a Cerâmica Pozzani de Jundiaí (SP), uma das maiores produtoras e exportadoras do ramo, que também encerrou as suas atividades há cerca de 10 anos.
Em sentido inverso, a partir da lei antidumping em 2013, as empresas de porcelana de mesa sobreviventes ganharam dinamismo, com expansão da produção e implantação de novas unidades. São os casos, por exemplo, da Oxford, hoje a maior fabricante nacional, que retomou a produção em São Bento do Sul e abriu uma nova fábrica em São Mateus (ES), do crescimento da produção das cerâmicas Brasília e Studio Tacto, ambas em Campo Largo (PR), bem como o reposicionamento da Porcelana Schmidt como uma das maiores empresas do ramo no país.

No Estado de São Paulo, observa-se também movimentações significativas, como o incremento da produção das unidades fabris, como da Porto Brasil e Scalla em Porto Ferreira. A expectativa é até mesmo de novos entrantes no mercado oriundos de outros segmentos do setor cerâmico, situação da empresa Tramontina, que anunciou em 2018 a instalação de uma fábrica em Moreno (PE).

Quanto ao segmento de porcelana e louça decorativa, não houve restrições legais à importação e, desta forma, a entrada de produtos do exterior permaneceu crescente até 2015, quando houve uma leve queda devido à retração econômica no país. Contudo, as importações continuam em níveis elevados, sobretudo a de louça decorativa, a mais expressiva em quantidade e valores. A conjunção de fatores restritivos, envolvendo importações expressivas e o tímido desempenho da economia brasileira nos últimos quatro anos, com forte queda na demanda, agravou a redução da produção nacional, provocando desemprego no segmento e até o fechamento de empresas, e só não trouxe mais desalento aos produtores de peças decorativas devido a alta do dólar, que inibiu um pouco a importação a partir de 2015 . 
As figuras 1 e 2 ilustram a evolução das importações de porcelana e louça de mesa. Constata-se que as compras externas desses tipos de produtos caíram abruptamente a partir de 2013, como reflexo positivo da lei antidumping, abrindo o mercado doméstico para as empresas nacionais em mais de US\$ 50 milhões/ano.

O mesmo não aconteceu com o segmento de produtos decorativos (figuras 3 e 4). Apesar de sua menor dimensão, as importações permaneceram no mesmo patamar anual de cerca de US\$ 10 milhões (Louça e Porcelana Decorativa).

\subsubsection{Cenário paulista}

O Estado de São Paulo conta com cerca de 150 a 200 empresas de porcelana e louça, que se encontram concentradas nos polos de Porto Ferreira e Pedreira.
Em Porto Ferreira, considerada a capital nacional da cerâmica artística, o produtores de louça de mesa vem se beneficiando da restrição das importações (lei antidumping) e da alta do dólar. As empresas desses produtos mostram relativo otimismo com a oportunidade de expansão da produção, bem como se verifica a movimentação de novos entrantes no segmento.

Como apontado para o cenário nacional, já entre as empresas de louça decorativa, as importações e a queda da demanda provocada pelo arrefecimento da economia vem ensejando um ambiente de negócios pouco otimista para o segmento, o que só foi amenizado, mais recentemente, pelo câmbio mais favorável. Medidas adotadas para realinhamento do segmento compreenderam o aumento da produção de faianças (tipo de cerâmica mais rústica,

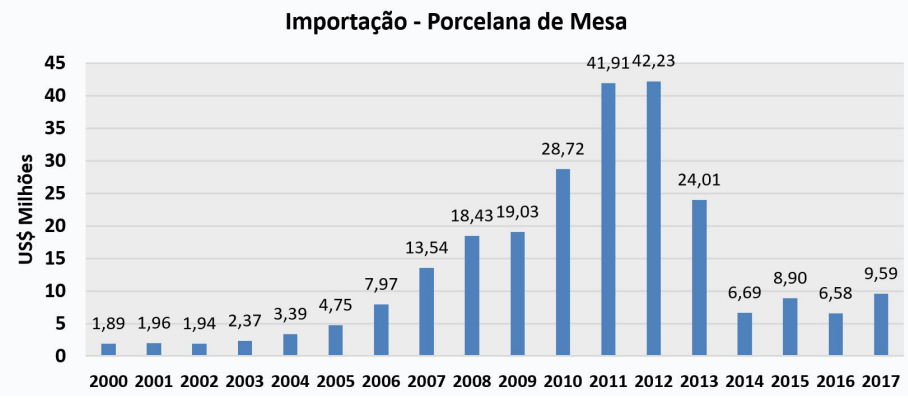

Figura 1 - Série histórica da importação de porcelana de mesa.

Fonte: MDIC (2018).

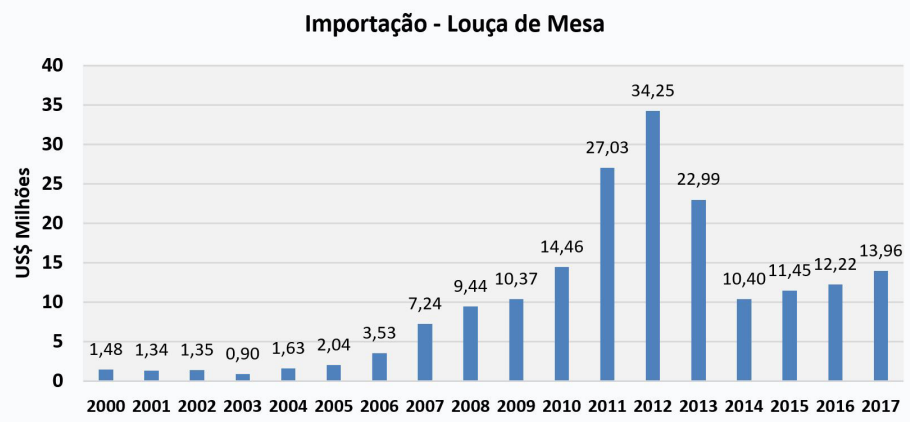

Figura 2 - Série histórica da importação de louça de mesa.

Fonte: MDIC (2018).

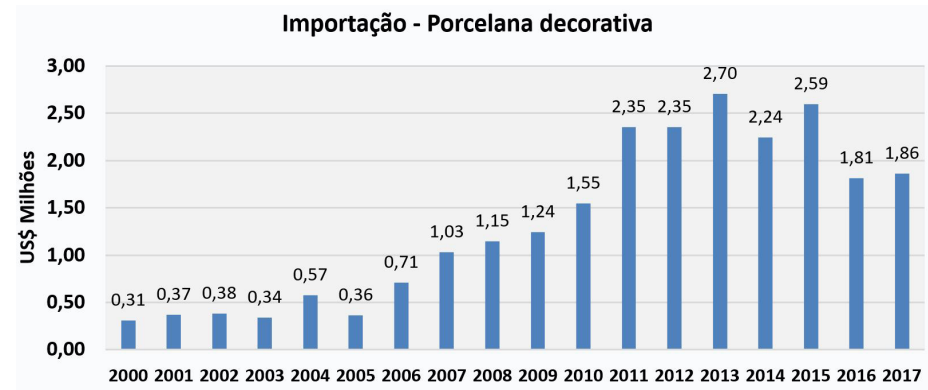

Figura 3 - Série histórica da importação de artigos decorativos de porcelana.

Fonte: MDIC (2018). 


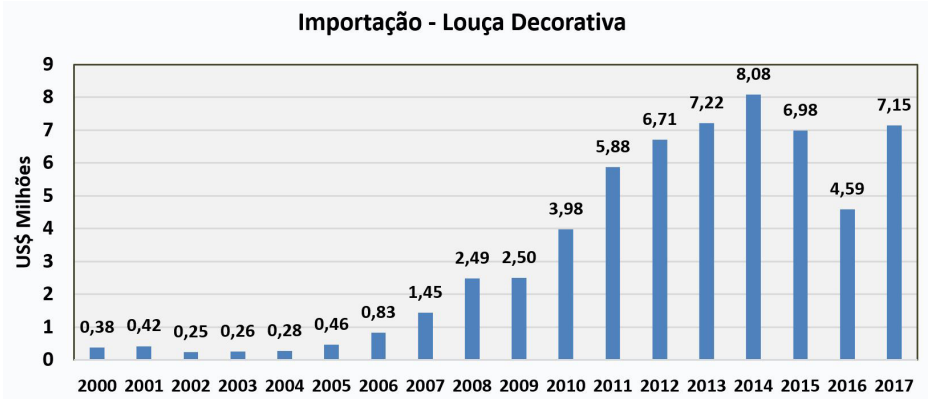

Figura 4 - Série histórica da importação de artigos decorativos de louça.

Fonte: São Paulo (1992).

de menor valor agregado), a substituição de fornos elétricos pelos a gás e a reprodução de peças similares às importadas, que deixaram de chegar ao país. Além disso, a instalação de uma unidade da empresa portuguesa Verbano no município, há cerca de quatro anos, aumentou a oferta de porcelana fina, e atraiu novos consumidores, na maioria revendedores das regiões Nordeste e Sul do país.

$\mathrm{O}$ parque produtivo de louça de mesa do município de Pedreira é o maior do estado, congregando cerca de 90 empresas que produzem uma grande diversidade de peças de uso doméstico, tais como: canecas, xícaras, pires, tigelas, bules, aparelhos de café e diferentes tipos de adornos como pinguins, vasos, estatuetas, dentre outros. Pelo perfil empresarial e a dinâmica econômica, trata-se de um dos arranjos produtivos locais - $\mathrm{APLs}^{2}$ de base mineral reconhecidos pelas instâncias governamentais, com grande impacto na geração local de emprego e renda.

A cidade que tem o codinome de "Capital da Porcelana", sendo conhecida como a maior produtora de gêneros de porcelana da América Latina, vem diversificando para artigos de louça, visando o barateamento e ampliação de seu mercado.

A mão de obra tem um peso elevado no custo de produção desse segmento cerâmico, pois a fabricação de grande variedade de tipos de peças impede a automação em larga escala. Sua participação em relação aos custos totais é em média superior a $35 \%$. Ganho competitivo importante ocorreu nesta última década, com a conversão da queima de fornos elétricos para gás natural. Já os custos com matéria-prima variam de $20 \%$ a $30 \%$.

O segmento cerâmico apresenta níveis elevados de perdas, que podem superar $20 \%$ em algumas fábricas, sobretudo pela variedade de peças produzidas. ${ }^{3}$

\footnotetext{
${ }^{2} \mathrm{O}$ termo arranjo produtivo local, ou simplesmente APL, tem sido utilizado no meio técnico-científico brasileiro e pelos organismos de governo e instituições de apoio ao setor empresarial para referir-se a concentrações geográficas de empresas e de instituições que se relacionam em torno de um setor ou de uma atividade econômica.

${ }^{3}$ Registra-se que há outras indústrias cerâmicas que também produzem artigos utilitários e de decoração no estado com base em massas da cerâmica vermelha, tais como potes, vasos, filtros de água etc. As empresas
}

\subsection{Processo Produtivo}

As porcelanas são produzidas com massas constituídas de substâncias minerais bastante puras - argilominerais (argila plástica e caulim), quartzo e feldspato, que são queimadas a temperaturas elevadas $\left(1.250^{\circ} \mathrm{C}\right.$ a $\left.1.350^{\circ} \mathrm{C}\right)$. Os produtos apresentam baixíssima porosidade ${ }^{4} \mathrm{e}$ compreendem peças de uso doméstico e de hotelaria, como pratos, xícaras, jogos de chá, bem como peças decorativas e artísticas.

As peças do tipo louça ou faiança são produtos de maior porosidade aberta e absorção d'água (> 3\% de absorção). Além das matérias-primas como argila, caulim, quartzo e feldspato, incorporam carbonatos (calcita e dolomita) em suas massas, que liberam $\mathrm{CO}_{2}$, e apresentam muita perda de massa no processamento térmico, cujas temperaturas são inferiores a $1.250{ }^{\circ} \mathrm{C}$. Esse fato reflete-se na menor densidade e resistência mecânica das peças da faiança em relação à porcelana. Seus produtos incluem aparelhos de jantar e chá, xícaras e canecas, e peças decorativas.

$\mathrm{Na}$ formulação das massas de faiança e porcelana, após a mistura adequada das matérias-primas, é realizada a moagem em moinho de bolas a úmido, para cominuição (ajuste fino da granulometria) e obtenção de uma suspenção homogênea, com cerca de $70 \%$ de sólido (barbotina). $\mathrm{Na}$ sequencia, ocorre a etapa de conformação das peças, que pode ser via úmida ou plástica.

Pelo processo de colagem (via úmida), a barbotina é depositada em moldes de gesso, sendo em seguida destacada do molde, seca, decorada e queimada. Esse processo abrange especialmente os produtos de formatos mais complexos, com formas curvas, ricas em detalhes, como asas de xícaras, bules, sopeiras, chaleiras e artigos de decoração.

No processamento plástico, a barbotina é desaguada em filtro-prensa, sendo que após atingir a umidade adequada, a massa é extrudada em formato cilíndrico - tarugos, que podem ser sazonados, seguindo para corte em tamanho

desses produtos encontram-se geralmente associadas aos polos de cerâmica vermelha, segmento industrial que foi abordado no primeiro artigo desta série (Cabral Junior et al., 2019a).

${ }^{4}$ A porosidade aberta é medida pela absorção de água da peça, que deve estar muito próxima de zero. 
adequado às peças a serem confeccionadas. A conformação final é feita por prensagem e tornearia. Esse processo tem maior produtividade, mas é indicado para peças com formas mais simples, sem muitos detalhes, como pratos e outros produtos mais "lisos".

O processo de queima em forno a gás natural é realizado em duas etapas (biqueima). Primeiro queima-se o biscoito e, em seguida, a peça esmaltada, com o controle de temperatura feito por meio de cones pirométricos. $\mathrm{Na}$ esmaltação são utilizados processos de imersão e decoração com pincel e, em alguns casos, aerográficos. Os esmaltes são desenvolvidos dentro da própria cerâmica e, por vezes, em parceria com os colorifícios.
A Figura 5 ilustra o fluxograma do processo de fabricação de porcelanas e faianças, desde a entrada das matérias-primas até a expedição do produto final.

\subsection{Sistema de Suprimento Mineral}

As indústrias do segmento consomem vários tipos de substâncias minerais. A massa de porcelana é constituída basicamente de argila plástica, caulim, feldspato, filito e quartzo, sendo que os vidrados que recobrem as peças recebem uma adição de dolomita. No caso de louças, as massas contêm também dolomita em substituição parcial ou total ao feldspato.

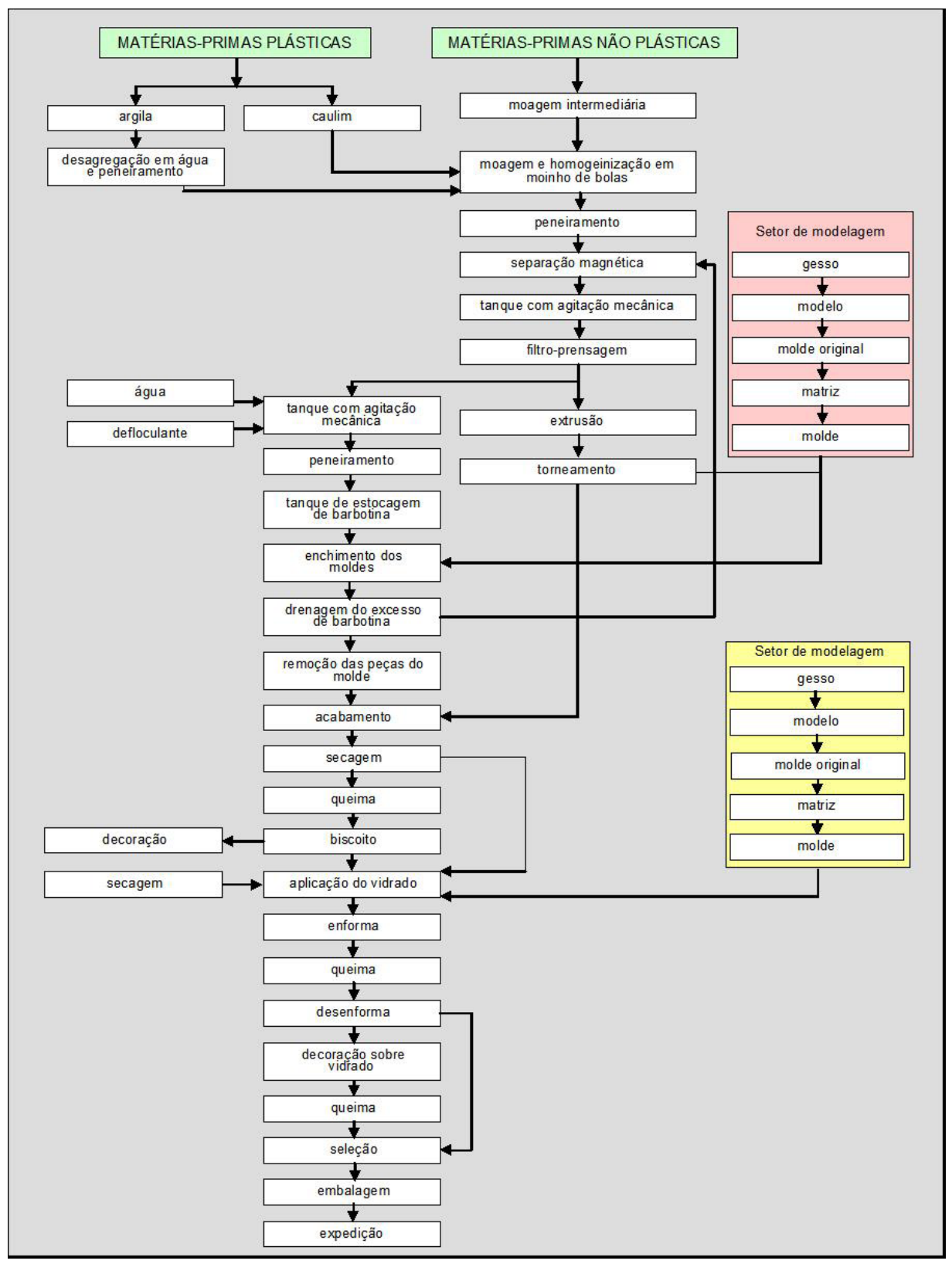

Figura 5 - Fluxograma do processo de fabricação de porcelana e louça. 
Pela sua importância na formulação das massas, merecem destaque as matérias-primas plásticas (argilas plásticas e caulins). As argilas plásticas aportam características reológicas e de plasticidade, importantes na fase de conformação, e propiciam a resistência mecânica a verde e a seco às peças; enquanto que o caulim, por tratar-se de argilas cauliníticas com menor teor de elementos cromóforos (Fe, Ti, etc.) incrementa a alvura das peças queimadas. Ambas têm ainda sua atuação estendida ao processamento térmico, transformando-se em compostos predominantemente cristalinos e definindo a cor do corpo cerâmico.

Nas empresas mais organizadas, as diferentes matérias-primas são estocadas em baias distintas, de onde seguem para a formulação da massa e carregamento nos moinhos de bola, onde permanecem por várias horas, até atingir a granulometria adequada, quando segue para o deságue e extrusão.

Quanto ao suprimento desses insumos minerais, há uma variação da oferta em termos de disponibilidade e qualidade das matérias-primas, como sinteticamente relacionadas a seguir:

- Argila plástica: caso mais crítico, com pouca possibilidade de oferta (depósitos e fornecedores), qualidade dos materiais média a ruim, preço alto.

- Dolomito e quartzo: oferta e qualidade satisfatórias.

- Feldspato: disponibilidade razoável, qualidade satisfatória, mas que sofre algumas variações mineralógicas e químicas, preço relativamente alto.

- Caulim: pouca disponibilidade, média a boa qualidade dos materiais, preços altos.

Analisando-se esse panorama de fornecimento, observa-se que é necessário ampliar a disponibilidade de oferta e qualidade da maioria das matérias-primas. O caso mais crítico refere-se às argilas plásticas.

Independente da necessária melhoria da qualidade das matérias-primas ofertadas in natura (propriedades e constância) por meio do sistema tradicional, um passo importante no aprimoramento do suprimento seria adoção em mais larga escala de fornecedores de massa pré-preparada a partir de centrais de processamento (centrais de massa).

Essa rota tecnológica já conta com experiências exitosas. É o caso da empresa Cermassa de Campo Largo (PR) que opera uma unidade de processamento e mistura de matérias-primas, aparelhada com laboratório para controle de qualidade das substâncias e produtos minerais. Produz diversos tipos de massas para cerâmica branca (plástica e não-plástica) utilizando matérias-primas de diversas regiões: argila de Pântano Grande (RS), argila de Suzano (SP), argila de Campo Alegre (PR), feldspato de Ponta Grossa (PR), filitos entre outros. O principal mercado da empresa são as empresas da região de Campo Largo. Em São Paulo, atende também diversas indústrias, principalmente na região de Porto Ferreira e Pedreira.

Apesar de não se dispor de informações precisas sobre a dimensão do mercado de louça e porcelana e, consequente, ter condições de indicar com maior exatidão o volume de matérias-primas consumidas, pode-se tentativamente inferir uma ordem de grandeza. Considerando a demanda anual do país em 40.000 toneladas e a participação da produção paulista em $30 \%$ no mercado nacional, o consumo anual do estado para o conjunto de matérias-primas deve situar-se na faixa de 12 mil toneladas. A Tabela 2 sintetiza, de forma estimada, o consumo estadual de substâncias minerais pelas indústrias de louça e porcelana.

\section{BALANÇO DO CONSUMO E PROJEÇÕES DA DEMANDA MINERAL PARA O PARQUE CERÂMICO PAULISTA}

O Quadro 1 apresenta o consumo consolidado de minerais industriais para todos os segmentos do parque industrial cerâmico do Estado de São Paulo, tendo como referência o ano de 2017.

Apesar das limitações das estimativas de demanda de matérias-primas minerais para alguns segmentos mais pulverizados e de difícil captação de informações, o dimensionamento calculado é satisfatório para uma visão global da quantidade consumida, possibilitando definir o montante dos principais bens minerais consumidos, o compartilhamento do suprimento por diferentes segmentos cerâmicos e estabelecer uma base de referência para a projeção da demanda futura da indústria cerâmica do Estado.

Constatou-se que o setor cerâmico paulista é responsável por uma demanda expressiva de minerais industriais, parte deles produzidos no território paulista, que corresponde a uma movimentação anual superior a 24 milhões toneladas.

A matriz de matérias-primas cerâmicas abarca 10 variedades principais de bens minerais, sendo que se destacam, em termos de quantidade, as argilas comum, de queima avermelhada, utilizadas pelos segmentos de Cerâmica Vermelha e de Revestimentos Via Seca, totalizando um consumo anual de 22,4 milhões de toneladas. Esse montante representa $93 \%$ do total de matérias-primas consumidas pela indústria cerâmica, sendo $60 \%$ pela Cerâmica Vermelha e o demais 33\% pelo segmento de Revestimentos. Importante lembrar, que apesar de serem argilas classificadas dentro da mesma tipologia (argilas comum), as rochas argilosas empregadas no cluster de Santa Gertrudes agregaram características especiais, de ocorrência limitada na região (Formação Corumbataí).

As outras oito principais substâncias minerais consumidas somam 1,75 milhões de toneladas, com maiores volumes

Tabela 2 - Consumo de matérias-primas minerais pelas indústrias de louça e porcelana no Estado de São Paulo - ano base 2017.

\begin{tabular}{lcc}
\hline \multicolumn{1}{c}{ MATÉRIA-PRIMA } & $\mathbf{\%}$ & Toneladas/Ano \\
\hline Argilas Plásticas Cauliníticas & 35 & 4.200 \\
Caulim & 15 & 1.800 \\
Feldspato & 30 & 3.600 \\
Quartzo & 10 & 1.200 \\
Calcário/Dolomito & 10 & 1.200 \\
TOTAL & $\mathbf{1 0 0}$ & $\mathbf{1 2 . 0 0 0}$ \\
\hline
\end{tabular}

Fonte: elaborado pelos autores. 
Quadro 1 - Minerais industriais cerâmicos consumidos pelo parque industrial do estado de São Paulo - ano base 2017.

\begin{tabular}{|c|c|c|c|c|c|c|c|c|c|c|c|c|}
\hline \multirow{2}{*}{\multicolumn{2}{|c|}{ INDÚSTRIA }} & \multicolumn{10}{|c|}{ Matérias-Primas (em 1.000 toneladas) } & \multirow{3}{*}{ SUBTOTAL } \\
\hline & & \multicolumn{3}{|c|}{ Plásticas } & \multicolumn{7}{|c|}{ Não Plásticas } & \\
\hline 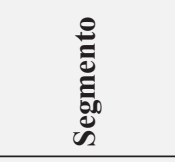 & 帝 & 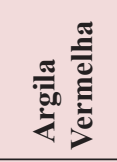 & 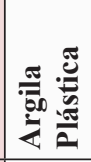 & 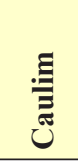 & 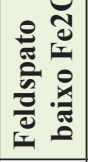 & 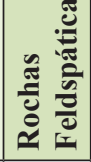 & 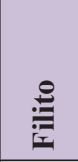 & $\frac{8}{\pi}$ & 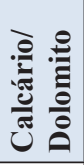 & 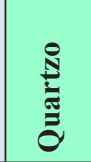 & 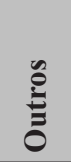 & \\
\hline $\begin{array}{c}1 \\
\text { Cerâmica } \\
\text { Vermelha } \\
\end{array}$ & $\begin{array}{l}\text { Blocos, lajes } \\
\quad \text { Telhas, } \\
\text { Agregado leve }\end{array}$ & $14.500,0$ & & & & & & & & & & $14.500,0$ \\
\hline \multirow{4}{*}{$\begin{array}{c}2 \\
\text { Revestimentos }\end{array}$} & Placas via seca & $7.900,0$ & & & & & & & & & & $7.900,0$ \\
\hline & $\begin{array}{c}\text { Placas via } \\
\text { úmida }\end{array}$ & & 115,5 & 16,5 & & & 135,0 & 13,2 & 29,7 & 6,6 & & 316,5 \\
\hline & $\begin{array}{l}\text { Porcelanato } \\
\text { técnico }\end{array}$ & & 75,0 & 21,4 & 84,7 & & 9,8 & 2,0 & 2,0 & 1,9 & 4,2 & 201,0 \\
\hline & $\begin{array}{l}\text { Porcelanato } \\
\text { esmaltado }\end{array}$ & & 343,0 & 51,5 & & & 352,3 & 25,7 & 25,7 & 17,2 & 0,8 & 816,2 \\
\hline \multicolumn{2}{|c|}{$\begin{array}{c}3 \\
\text { Louça Sanitária }\end{array}$} & & 20,0 & 5,8 & & 30,0 & 12,0 & & & 2,4 & 3,6 & 73,8 \\
\hline \multicolumn{2}{|c|}{$\begin{array}{c}4 \\
\text { Louça e Porcelana } \\
\text { de Mesa e Decorativa }\end{array}$} & & 4,2 & 1,8 & 3,6 & & & & 1,2 & 1,2 & & 12,0 \\
\hline \multicolumn{2}{|c|}{$\begin{array}{c}5 \\
\text { Colorifícios (SP) } \\
\end{array}$} & & 23,2 & 29,5 & 90,0 & & & 5,8 & 19,0 & 117,0 & 17,6 & 302,1 \\
\hline \multicolumn{2}{|c|}{$\begin{array}{c}6 \\
\text { Isoladores }\end{array}$} & & 7,5 & 6,0 & 9,0 & & & 1,5 & & 6,0 & & 30,0 \\
\hline \multicolumn{2}{|c|}{ SUBTOTAL } & $22.400,0$ & 588,4 & 132,5 & 187,3 & 30,0 & 509,1 & 48,2 & 77,6 & 152,3 & 26,2 & \multirow{2}{*}{$24.151,6$} \\
\hline OTAL & & & & & & & & & & & & \\
\hline
\end{tabular}

*Obs.: outras matérias-primas - inclui gama variada de substâncias minerais, tais como bentonita, volastonita, diopsídio, zirconita, entre outras. Fonte: elaborado pelos autores.

de argilas plásticas de queima clara, filito, feldspato, quartzo, caulim e rochas carbonáticas (Figura 6).

Embora a grande discrepância entre as quantidades consumidas de argilas comum e as demais oito substâncias possa induzir a uma menor importância dessas últimas para a indústria cerâmica e terem menores dificuldades técnico-econômicas de suprimento, o que ocorre é exatamente ao contrário. Trata-se de substâncias minerais essenciais aos vários segmentos cerâmicos, com depósitos de ocorrência mais rara, sendo a maior parte de pequeno porte e localizada relativamente distantes dos centros consumidores. Algumas substâncias como feldspato, talco, argilas plásticas e caulim contam com parcela relevante do suprimento proveniente de outros estados, sendo que as duas primeiras não são praticamente produzidos em São Paulo.

A projeção de demanda futura de insumos minerais para uma indústria constitui uma importante referência para orientar políticas públicas de aprimoramento competitivo de cadeias produtivas, como também para identificar oportunidades de mínero-negócios para o setor empresarial. Isto é ainda mais evidente para uma indústria intensiva em bens minerais, como é o caso do setor cerâmico.
A atual conjuntura político-econômica do país dificulta sobremaneira a construção de cenários econômicos, sobretudo no que tange ao prognóstico de crescimento do produto interno bruto (PIB) para os próximos anos.

Nesse contexto de incertezas elevadas, buscou-se efetuar uma projeção de demanda para cada uma das dez principais substâncias minerais consumidas pelo parque cerâmico paulista, dentro de uma banda de variação de

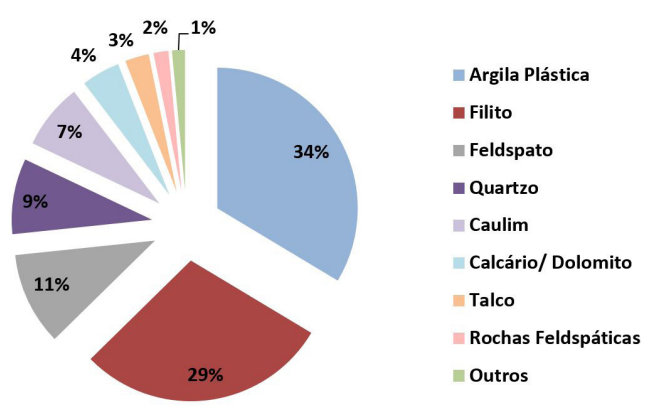

Figura 6 - Minerais industriais cerâmicos (exceto argilas comum) consumidos pelo parque cerâmico paulista. 
crescimento compatível com a dinâmica dessa indústria, limitando-se ao horizonte de 2030.

As referências para estabelecimento dos percentuais de crescimento foram:

- Cenário central (neutro) - taxa de crescimento anual de 2,5\%, considerado mais factível para o crescimento do setor cerâmico e que considerou, basicamente, o comportamento histórico dessa indústria em relação ao PIB Brasil e ao PIB da Construção nos últimos 25 anos;

- Cenário pessimista - taxa de crescimento anual de $1,0 \%$, como limiar inferior; e

Tabela 3 - Projeção de demanda de argila para a indústria de Cerâmica Vermelha (SP) - 2018 a 2030.

\begin{tabular}{|c|c|c|c|}
\hline \multirow{5}{*}{ Ano } & \multicolumn{3}{|c|}{ Argila - Cerâmica Vermelha } \\
\hline & \multicolumn{3}{|c|}{ Cenários } \\
\hline & Pessimista & Neutro & Otimista \\
\hline & $1 \% / a n o$ & $2,5 \% /$ ano & 4\%/ano \\
\hline & $(\mathrm{em} 1.000 \mathrm{t})$ & $(\mathrm{em} 1.000 \mathrm{t})$ & $(\mathrm{em} 1.000 \mathrm{t})$ \\
\hline 2018 & $14.500,0$ & 30,0 & 30,0 \\
\hline 2019 & $14.645,0$ & $14.862,5$ & $15.080,0$ \\
\hline 2020 & $14.791,5$ & $15.234,1$ & $15.683,2$ \\
\hline 2021 & $14.939,4$ & $15.614,9$ & $16.310,5$ \\
\hline 2022 & $15.088,8$ & $16.005,3$ & $16.962,9$ \\
\hline 2023 & $15.239,6$ & $16.405,4$ & $17.641,5$ \\
\hline 2024 & $15.392,0$ & $16.815,6$ & $18.347,1$ \\
\hline 2025 & $15.546,0$ & $17.235,9$ & $19.081,0$ \\
\hline 2026 & $15.701,4$ & $17.666,8$ & $19.844,3$ \\
\hline 2027 & $15.858,4$ & $18.108,5$ & $20.638,0$ \\
\hline 2028 & $16.017,0$ & $18.561,2$ & $21.463,5$ \\
\hline 2029 & $16.177,2$ & $19.025,3$ & $22.322,1$ \\
\hline 2030 & $16.339,0$ & $19.500,9$ & $23.215,0$ \\
\hline
\end{tabular}

Tabela 4 - Projeção de argila para a indústria de Revestimentos Via Seca (SP) - 2018 a 2030.

\begin{tabular}{|c|c|c|c|}
\hline \multirow{5}{*}{ Ano } & \multicolumn{3}{|c|}{ Argila - Revestimento Via Seca } \\
\hline & \multicolumn{3}{|c|}{ Cenários } \\
\hline & Pessimista & Neutro & Otimista \\
\hline & $1 \% /$ ano & $2,5 \% /$ ano & $4 \% /$ ano \\
\hline & $(\mathrm{em} 1.000 \mathrm{t})$ & $(\mathrm{em} 1.000 \mathrm{t})$ & $(\mathrm{em} 1.000 \mathrm{t})$ \\
\hline 2018 & $7.900,0$ & 30,0 & 30,0 \\
\hline 2019 & $7.979,0$ & $8.097,5$ & $8.216,0$ \\
\hline 2020 & $8.058,8$ & $8.299,9$ & $8.544,6$ \\
\hline 2021 & $8.139,4$ & $8.507,4$ & $8.886,4$ \\
\hline 2022 & $8.220,8$ & $8.720,1$ & $9.241,9$ \\
\hline 2023 & $8.303,0$ & $8.938,1$ & $9.611,6$ \\
\hline 2024 & $8.386,0$ & $9.161,6$ & $9.996,0$ \\
\hline 2025 & $8.469,9$ & $9.390,6$ & $10.395,9$ \\
\hline 2026 & $8.554,6$ & $9.625,4$ & $10.811,7$ \\
\hline 2027 & $8.640,1$ & $9.866,0$ & $11.244,2$ \\
\hline 2028 & $8.726,5$ & $10.112,7$ & $11.693,9$ \\
\hline 2029 & $8.813,8$ & $10.365,5$ & $12.161,7$ \\
\hline 2030 & $8.901,9$ & $10.624,6$ & $12.648,2$ \\
\hline
\end{tabular}

- Cenário otimista - taxa de crescimento anual de $4,0 \%$, como limiar superior.

A expectativa é que a tendência de expansão de consumo das substâncias deva se situar dentro dessa faixa de valores indicados, entre $1 \%$ e $4 \%$ para os próximos 11 anos. Os resultados encontram-se sintetizados nas tabelas 3 a 12 .

Não obstante a esse padrão médio prognosticado, certamente não se espera um comportamento homogêneo de variação de demanda para os minerais industriais cerâmicos. Além do crescimento global da economia do país, outros vetores mais específicos interferem diretamente na dinâmica no setor, destacando-se, o comportamento

Tabela 5 - Projeção da demanda de argilas plásticas para o setor cerâmico (SP) - 2018 a 2030.

\begin{tabular}{|c|c|c|c|}
\hline \multirow{5}{*}{ Ano } & \multicolumn{3}{|c|}{ Argila Plástica } \\
\hline & \multicolumn{3}{|c|}{ Cenários } \\
\hline & Pessimista & Neutro & Otimista \\
\hline & $1 \% /$ ano & 2,5\%/ano & 4\%/ano \\
\hline & $(\mathrm{em} 1.000 \mathrm{t})$ & $(\mathrm{em} 1.000 \mathrm{t})$ & $(\mathrm{em} 1.000 \mathrm{t})$ \\
\hline 2018 & 588,4 & 30,0 & 30,0 \\
\hline 2019 & 594,3 & 603,1 & 611,9 \\
\hline 2020 & 600,2 & 618,2 & 636,4 \\
\hline 2021 & 606,2 & 633,6 & 661,9 \\
\hline 2022 & 612,3 & 649,5 & 688,3 \\
\hline 2023 & 618,4 & 665,7 & 715,9 \\
\hline 2024 & 624,6 & 682,4 & 744,5 \\
\hline 2025 & 630,8 & 699,4 & 774,3 \\
\hline 2026 & 637,2 & 716,9 & 805,3 \\
\hline 2027 & 643,5 & 734,8 & 837,5 \\
\hline 2028 & 650,0 & 753,2 & 871,0 \\
\hline 2029 & 656,5 & 772,0 & 905,8 \\
\hline 2030 & 663,0 & 791,3 & 942,0 \\
\hline
\end{tabular}

Tabela 6 - Projeção de demanda de filito para o setor cerâmico (SP) - 2018 a 2030.

\begin{tabular}{|c|c|c|c|}
\hline \multirow{5}{*}{ Ano } & \multicolumn{3}{|c|}{ Filito } \\
\hline & \multicolumn{3}{|c|}{ Cenários } \\
\hline & Pessimista & Neutro & Otimista \\
\hline & $1 \% /$ ano & 2,5\%/ano & 4\%/ano \\
\hline & $(\mathrm{em} 1.000 \mathrm{t})$ & $(\mathrm{em} 1.000 \mathrm{t})$ & $(\mathrm{em} 1.000 \mathrm{t})$ \\
\hline 2018 & 509,1 & 30,0 & 30,0 \\
\hline 2019 & 514,2 & 521,8 & 529,5 \\
\hline 2020 & 519,3 & 534,9 & 550,6 \\
\hline 2021 & 524,5 & 548,2 & 572,7 \\
\hline 2022 & 529,8 & 562,0 & 595,6 \\
\hline 2023 & 535,1 & 576,0 & 619,4 \\
\hline 2024 & 540,4 & 590,4 & 644,2 \\
\hline 2025 & 545,8 & 605,2 & 669,9 \\
\hline 2026 & 551,3 & 620,3 & 696,7 \\
\hline 2027 & 556,8 & 635,8 & 724,6 \\
\hline 2028 & 562,4 & 651,7 & 753,6 \\
\hline 2029 & 568,0 & 668,0 & 783,7 \\
\hline 2030 & 573,7 & 684,7 & 815,1 \\
\hline
\end{tabular}


Tabela 7 - Projeção de demanda de feldspato para o setor cerâmico (SP) - 2018 a 2030.

\begin{tabular}{|c|c|c|c|}
\hline \multirow{5}{*}{ Ano } & \multicolumn{3}{|c|}{ Feldspato } \\
\hline & \multicolumn{3}{|c|}{ Cenários } \\
\hline & Pessimista & Neutro & Otimista \\
\hline & $1 \% /$ ano & $2,5 \% /$ ano & $4 \% /$ ano \\
\hline & $(\mathrm{em} 1.000 \mathrm{t})$ & $(\mathrm{em} 1.000 \mathrm{t})$ & $(\mathrm{em} 1.000 \mathrm{t})$ \\
\hline 2018 & 187,3 & 30,0 & 30,0 \\
\hline 2019 & 189,2 & 192,0 & 194,8 \\
\hline 2020 & 191,1 & 196,8 & 202,6 \\
\hline 2021 & 193,0 & 201,7 & 210,7 \\
\hline 2022 & 194,9 & 206,7 & 219,1 \\
\hline 2023 & 196,9 & 211,9 & 227,9 \\
\hline 2024 & 198,8 & 217,2 & 237,0 \\
\hline 2025 & 200,8 & 222,6 & 246,5 \\
\hline 2026 & 202,8 & 228,2 & 256,3 \\
\hline 2027 & 204,8 & 233,9 & 266,6 \\
\hline 2028 & 206,9 & 239,8 & 277,2 \\
\hline 2029 & 209,0 & 245,8 & 288,3 \\
\hline 2030 & 211,1 & 251,9 & 299,9 \\
\hline
\end{tabular}

Tabela 8 - Projeção de demanda de quartzo para o setor cerâmico (SP) -2018 a 2030.

\begin{tabular}{|c|c|c|c|}
\hline \multirow{5}{*}{ Ano } & \multicolumn{3}{|c|}{ Quartzo } \\
\hline & \multicolumn{3}{|c|}{ Cenários } \\
\hline & Pessimista & Neutro & Otimista \\
\hline & $1 \% /$ ano & $2,5 \% /$ ano & 4\%/ano \\
\hline & $(\mathrm{em} 1.000 \mathrm{t})$ & $(\mathrm{em} 1.000 \mathrm{t})$ & $(\mathrm{em} 1.000 \mathrm{t})$ \\
\hline 2018 & 152,3 & 30,0 & 30,0 \\
\hline 2019 & 153,8 & 156,1 & 158,4 \\
\hline 2020 & 155,4 & 160,0 & 164,7 \\
\hline 2021 & 156,9 & 164,0 & 171,3 \\
\hline 2022 & 158,5 & 168,1 & 178,2 \\
\hline 2023 & 160,1 & 172,3 & 185,3 \\
\hline 2024 & 161,7 & 176,6 & 192,7 \\
\hline 2025 & 163,3 & 181,0 & 200,4 \\
\hline 2026 & 164,9 & 185,6 & 208,4 \\
\hline 2027 & 166,6 & 190,2 & 216,8 \\
\hline 2028 & 168,2 & 195,0 & 225,4 \\
\hline 2029 & 169,9 & 199,8 & 234,5 \\
\hline 2030 & 171,6 & 204,8 & 243,8 \\
\hline
\end{tabular}

da indústria da construção (habitação e infraestrutura), como já referido e, dependendo do segmento, mudanças tecnológicas no processo produtivo para introdução de novos produtos, no perfil do mercado (p.ex. tendência do crescimento da produção de porcelanato em detrimento aos revestimentos tradicionais via úmida e via seca) e existência de barreiras comerciais para produtos importados (p.ex. porcelanato, segmento de louça e porcelana de mesa). Isto sem considerar a capacidade de maior inserção dos vários segmentos dessa indústria no mercado internacional.

Substância com expectativa mais elevada de expansão é a argila plástica, cuja demanda será ditada, mormente,
Tabela 9 - Projeção de demanda de caulim para o setor cerâmico (SP) -2018 a 2030.

\begin{tabular}{|c|c|c|c|}
\hline \multirow{5}{*}{ Ano } & \multicolumn{3}{|c|}{ Caulim } \\
\hline & \multicolumn{3}{|c|}{ Cenários } \\
\hline & Pessimista & Neutro & Otimista \\
\hline & $1 \% /$ ano & $2,5 \% /$ ano & 4\%/ano \\
\hline & $(\mathrm{em} 1.000 \mathrm{t})$ & $(\operatorname{em~} 1.000 \mathrm{t})$ & $(\mathrm{em} 1.000 \mathrm{t})$ \\
\hline 2018 & 132,5 & 30,0 & 30,0 \\
\hline 2019 & 133,8 & 135,8 & 137,8 \\
\hline 2020 & 135,2 & 139,2 & 143,3 \\
\hline 2021 & 136,5 & 142,7 & 149,0 \\
\hline 2022 & 137,9 & 146,3 & 155,0 \\
\hline 2023 & 139,3 & 149,9 & 161,2 \\
\hline 2024 & 140,7 & 153,7 & 167,7 \\
\hline 2025 & 142,1 & 157,5 & 174,4 \\
\hline 2026 & 143,5 & 161,4 & 181,3 \\
\hline 2027 & 144,9 & 165,5 & 188,6 \\
\hline 2028 & 146,4 & 169,6 & 196,1 \\
\hline 2029 & 147,8 & 173,9 & 204,0 \\
\hline 2030 & 149,3 & 178,2 & 212,1 \\
\hline
\end{tabular}

Tabela 10 - Projeção de demanda de calcário e dolomito para o setor cerâmico (SP) - 2018 a 2030.

\begin{tabular}{|c|c|c|c|}
\hline \multirow{5}{*}{ Ano } & \multicolumn{3}{|c|}{ Calcário e Dolomito } \\
\hline & \multicolumn{3}{|c|}{ Cenários } \\
\hline & Pessimista & Neutro & Otimista \\
\hline & $1 \% /$ ano & $2,5 \% /$ ano & $4 \% /$ ano \\
\hline & $(\mathrm{em} 1.000 \mathrm{t})$ & $(\mathrm{em} 1.000 \mathrm{t})$ & $(\mathrm{em} 1.000 \mathrm{t})$ \\
\hline 2018 & 77,6 & 30,0 & 30,0 \\
\hline 2019 & 78,4 & 79,5 & 80,7 \\
\hline 2020 & 79,2 & 81,5 & 83,9 \\
\hline 2021 & 80,0 & 83,6 & 87,3 \\
\hline 2022 & 80,8 & 85,7 & 90,8 \\
\hline 2023 & 81,6 & 87,8 & 94,4 \\
\hline 2024 & 82,4 & 90,0 & 98,2 \\
\hline 2025 & 83,2 & 92,2 & 102,1 \\
\hline 2026 & 84,0 & 94,5 & 106,2 \\
\hline 2027 & 84,9 & 96,9 & 110,4 \\
\hline 2028 & 85,7 & 99,3 & 114,9 \\
\hline 2029 & 86,6 & 101,8 & 119,5 \\
\hline 2030 & 87,4 & 104,4 & 124,2 \\
\hline
\end{tabular}

pela dinâmica da produção de porcelanato no Estado. Para se exemplificar o impacto que o crescimento do consumo desse bem mineral pode provocar no mercado produtor mineral, concretizando o cenário mais otimista, que neste caso é bastante factível, o acréscimo de consumo anual no final de 12 anos será da ordem de 450.000 toneladas/ano. Considerando que as minas atuais já operam, em grande parte, em plena capacidade e possuem pequenas reservas, para fazer frente a esse aumento na demanda seriam necessárias cerca de 10 novas minas em operação (média de produção anual de 40.000 a 60.000). 
Tabela 11 - Projeção de demanda de talco para o setor cerâmico (SP) -2018 a 2030.

\begin{tabular}{|c|c|c|c|}
\hline \multirow{5}{*}{ Ano } & \multicolumn{3}{|c|}{ Talco } \\
\hline & \multicolumn{3}{|c|}{ Cenários } \\
\hline & Pessimista & Neutro & Otimista \\
\hline & $1 \% /$ ano & 2,5\%/ano & $4 \% /$ ano \\
\hline & $(\mathrm{em} 1.000 \mathrm{t})$ & $(\mathrm{em} 1.000 \mathrm{t})$ & $(\mathrm{em} 1.000 \mathrm{t})$ \\
\hline 2018 & 48,2 & 30,0 & 30,0 \\
\hline 2019 & 48,7 & 49,4 & 50,1 \\
\hline 2020 & 49,2 & 50,6 & 52,1 \\
\hline 2021 & 49,7 & 51,9 & 54,2 \\
\hline 2022 & 50,2 & 53,2 & 56,4 \\
\hline 2023 & 50,7 & 54,5 & 58,6 \\
\hline 2024 & 51,2 & 55,9 & 61,0 \\
\hline 2025 & 51,7 & 57,3 & 63,4 \\
\hline 2026 & 52,2 & 58,7 & 66,0 \\
\hline 2027 & 52,7 & 60,2 & 68,6 \\
\hline 2028 & 53,2 & 61,7 & 71,3 \\
\hline 2029 & 53,8 & 63,2 & 74,2 \\
\hline 2030 & 54,3 & 64,8 & 77,2 \\
\hline
\end{tabular}

Tabela 12 - Projeção de demanda de rochas feldspáticas para o setor cerâmico (SP) - 2018 a 2030.

\begin{tabular}{|c|c|c|c|}
\hline \multirow{5}{*}{ Ano } & \multicolumn{3}{|c|}{ Rochas Feldspáticas } \\
\hline & \multicolumn{3}{|c|}{ Cenários } \\
\hline & Pessimista & Neutro & Otimista \\
\hline & $1 \% /$ ano & 2,5\%/ano & $4 \% /$ ano \\
\hline & $(\mathrm{em} 1.000 \mathrm{t})$ & $($ (em $1.000 t)$ & $(\mathrm{em} 1.000 \mathrm{t})$ \\
\hline 2018 & 30,0 & 30,0 & 30,0 \\
\hline 2019 & 30,3 & 30,8 & 31,2 \\
\hline 2020 & 30,6 & 31,5 & 32,4 \\
\hline 2021 & 30,9 & 32,3 & 33,7 \\
\hline 2022 & 31,2 & 33,1 & 35,1 \\
\hline 2023 & 31,5 & 33,9 & 36,5 \\
\hline 2024 & 31,8 & 34,8 & 38,0 \\
\hline 2025 & 32,2 & 35,7 & 39,5 \\
\hline 2026 & 32,5 & 36,6 & 41,1 \\
\hline 2027 & 32,8 & 37,5 & 42,7 \\
\hline 2028 & 33,1 & 38,4 & 44,4 \\
\hline 2029 & 33,5 & 39,4 & 46,2 \\
\hline 2030 & 33,8 & 40,3 & 48,0 \\
\hline
\end{tabular}

\section{ANÁLISE ESTRATÉGICA DO SETOR MÍNERO-CERÂMICO}

Buscou-se efetuar uma análise sucinta do ambiente produtivo e de negócios do parque mínero-cerâmico paulista, ao qual estão atrelados fatores positivos e oportunidades que, se potencializados, poderão concorrer para consolidar o seu dinamismo, bem como fatores negativos e deficiências que inibem a competitividade, e que deverão ser caracterizados e superados na medida do possível.
Para sintetizar fatores de competividade de empresas e negócios em um esquema simplificado, dentre as diversas técnicas de avaliação setorial, optou-se por utilizar a ferramenta de Análise SWOT ${ }^{5}$. O resultado dessa avaliação é a criação de uma matriz, onde são identificados os principais fatores internos para serem trabalhados pelo setor, para maximização de diferenciais competitivos e diminuição ou eliminação de fraquezas, e os pontos externos que demandam atenção, de forma a aproveitar as oportunidades reconhecidas e minimizar o efeito e o impacto das ameaças vislumbradas.

Nesse sentido, foram estruturadas seis matrizes (Figuras 7 a 12), uma para cada um dos segmentos analisados da indústria cerâmica (vermelha, revestimentos, colorifícios sanitários, isoladores, louças e porcelanas), nas quais estão indicadas algumas das forças, fraquezas, oportunidades e ameaças detectadas. Sem a pretensão de esgotar o assunto, esse diagnóstico estratégico visou, sobretudo, trazer elementos que fundamentem a formulação de políticas para aprimoramento do sistema de suprimento mineral ao setor cerâmico estadual.

Considerando as implicações do ambiente empresarial e de negócios delineados para o setor cerâmico sobre o sistema de suprimento mineral, bem como as suas próprias características intrínsecas, sistêmicas e estruturais, o mesmo tipo de análise pode ser replicado ao setor produtivo de minerais industriais cerâmicos, cujas observações destacadas (Quadro 2), em muitos casos extrapolam, o domínio do território estadual.

Finalizando, é dado relevo a algumas inciativas estruturantes, consideradas estratégicas para o aprimoramento do suprimento mineral do parque cerâmico paulista e que devem ser apoiadas por políticas públicas setoriais:

a) Promover etapa complementar deste estudo, que deverá envolver o mapeamento da cadeia de fornecedores de matérias-primas para o setor cerâmico, caracterizando em detalhe - dotação mineral (reservas e potencial geológico), produção (quantidade e valores), estrutura empresarial (número de mineradores, tipos de gestão, origem do capital), tecnologias (pesquisa mineral, lavra e beneficiamento), questões ambientais (impactos, fatores críticos, medidas mitigadoras - situação atual e melhorias desejáveis) e plano de aprimoramento competitivo.

b) Elaborar e apoiar a institucionalização do Ordenamento Territorial Geomineiro - OTGM, como forma de inserir a atividade de mineração nos instrumentos de planejamento territorial, caso dos planos diretores municipais, para garantir a

${ }^{5}$ SWOT - do acrônimo em inglês Strengh (Força), Weakness (Fraqueza), Opportunity (Oportunidade), Threat (Ameaça). 
Quadro 2 - Desafios e oportunidade para o aprimoramento do sistema de suprimento mineral da indústria cerâmica no Estado de São Paulo. a) Forças

- Geodiversidade favorável, determinante da existência de depósitos de matérias-primas tradicionais e inovadoras, com vasta distribuição geográfica, relativizada no contexto estadual.

- Grande dimensão do mercado consumidor cerâmico brasileiro.

- Modernas tecnologias de produção mineral necessárias à modernização das pequenas e médias empresas de minerais industriais cerâmicos são de amplo domínio do meio técnico-científico e empresarial do país, e que já vem sendo aplicadas por empresas líderes correlatas no setor (p. ex. mineração de bens metálicos).

\section{b) Fraquezas}

- Parcela importante do setor é constituída por pequenas empresas de mineração com carências tecnológicas, gestão empresarial inadequada e dificuldade de acesso a crédito.

- Matérias-primas de baixo valor agregado e operações com baixa margem de lucratividade.

- Dimensões reduzidas das jazidas (exceto argila comum), que limitam a mecanização e produção em larga escala.

- Grandes distâncias entre algumas jazidas importantes e centros consumidores ceramistas.

- Consideração inadequada de sustentabilidade dos empreendimentos, com carências no controle e recuperação ambiental das áreas mineradas, na geração de resíduos e na interação com as comunidades de entorno.

\section{c) Oportunidades}

- Aumento da demanda futura do mercado interno.

- Identificação de novas jazidas de maior porte, com maior proximidade dos centros consumidores do ESP.

- Implantação de centrais de massa (incremento dos fatores escala, qualidade, constância e homogeneidade das matérias-primas).

- Implantação e fortalecimento de APLs de base mineral (incremento do associativismo, cooperativismo e fortalecimento da governança na produção mineral).

- Desenvolvimento de formulações de massa a partir de matérias-primas do ESP (“tropicalização de massas").

- Desenvolvimento de fontes alternativas ao feldspato de pegmatito no ESP (rotas inovativas de beneficiamento de rochas alcalinas e graníticas).

- Aproveitamento de resíduos minerais.

d) Ameaças

- Deficiência sistêmica - logística de transporte (essencialmente unimodal - rodoviário, de alto custo).

- Conflitos quanto ao uso e à ocupação do solo - falta de ordenamento territorial (OTGM) principalmente nos polos de cerâmica vermelha.

- Aumento de restrições ambientais (sobretudo para extração de argilas aluvionares).

- Morosidade no licenciamento ambiental.

- Exaustão de jazidas mais próximas aos centros consumidores do ESP - argilas plásticas, caulim e filito.

- Importação de matérias-primas de maior valor agregado (caulim e ball clays).

Fonte: MDIC (2018).

disponibilidade de matérias-primas especialmente nos polos de Cerâmica Vermelha e de Revestimento. ${ }^{6}$

c) Atuar para a consolidação dos APLs mínero-cerâmicos no sentido do fortalecimento das estruturas de governança local, de estímulo a maior articulação e cooperação entre os diversos atores que interagem localmente no setor, do engajamento do poder público para promover a inclusão da mineração no ordenamento territorial da região e do estreitamento dos vínculos entre os APLs e o Sistema Paulista

\footnotetext{
${ }^{6}$ O OTGM constitui uma modalidade especializada de Ordenamento Territorial, cujo objetivo tem como eixo central possibilitar o planejamento e a gestão da disponibilidade dos recursos minerais, de modo compatível com outras formas e prioridades de uso e ocupação existentes ou programadas para esse espaço físico, harmonizada com atributos e recursos ambientais existentes (Cabral Junior; Gamba, 2016).
}

de CT\&I, visando colocar o conhecimento gerado nessas instituições a serviço do sistema produtivo.

d) Realizar levantamentos geológicos e prospectivos que embasem a identificação de jazidas de minerais cerâmicos. Para tanto, deve-se levar em conta a importância da incorporação de novas tecnologias nas campanhas exploratórias, como a avaliação geológica por meio de modelagem metalogenética, uso de métodos geofísicos e geoquímicos, e tecnologias computacionais na quantificação dos depósitos, as quais são usuais na prospecção de minerais metálicos, e, praticamente, não empregadas aos minerais industriais cerâmicos. ${ }^{7}$

\footnotetext{
${ }^{7}$ Instituições que podem se engajar em trabalhos com este enfoque prospectivo são o Serviço Geológico do Brasil - CPRM e centros de pesquisa e inovação que atuam nas áreas de Geologia, Engenharia de Minas e Tecnologia Mineral.
} 


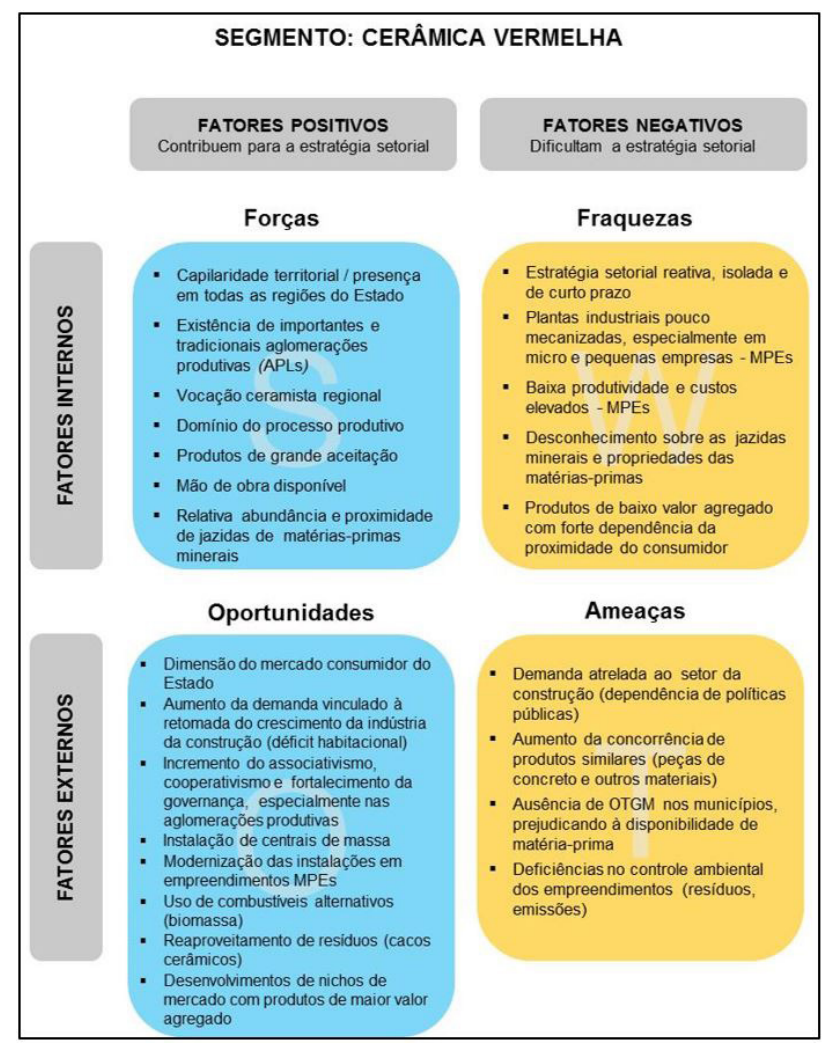

Figura 7 - Análise estratégica do segmento de Cerâmica Vermelha no Estado de São Paulo.

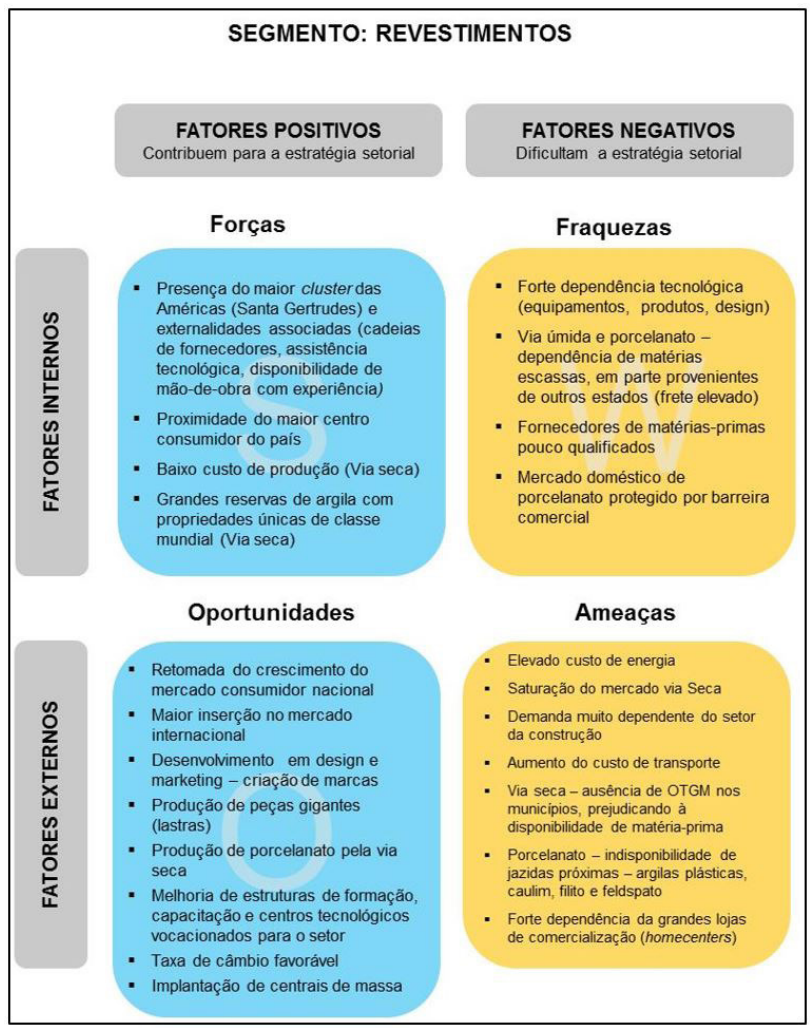

Figura 8 - Análise estratégica do segmento de Revestimentos no Estado de São Paulo. 


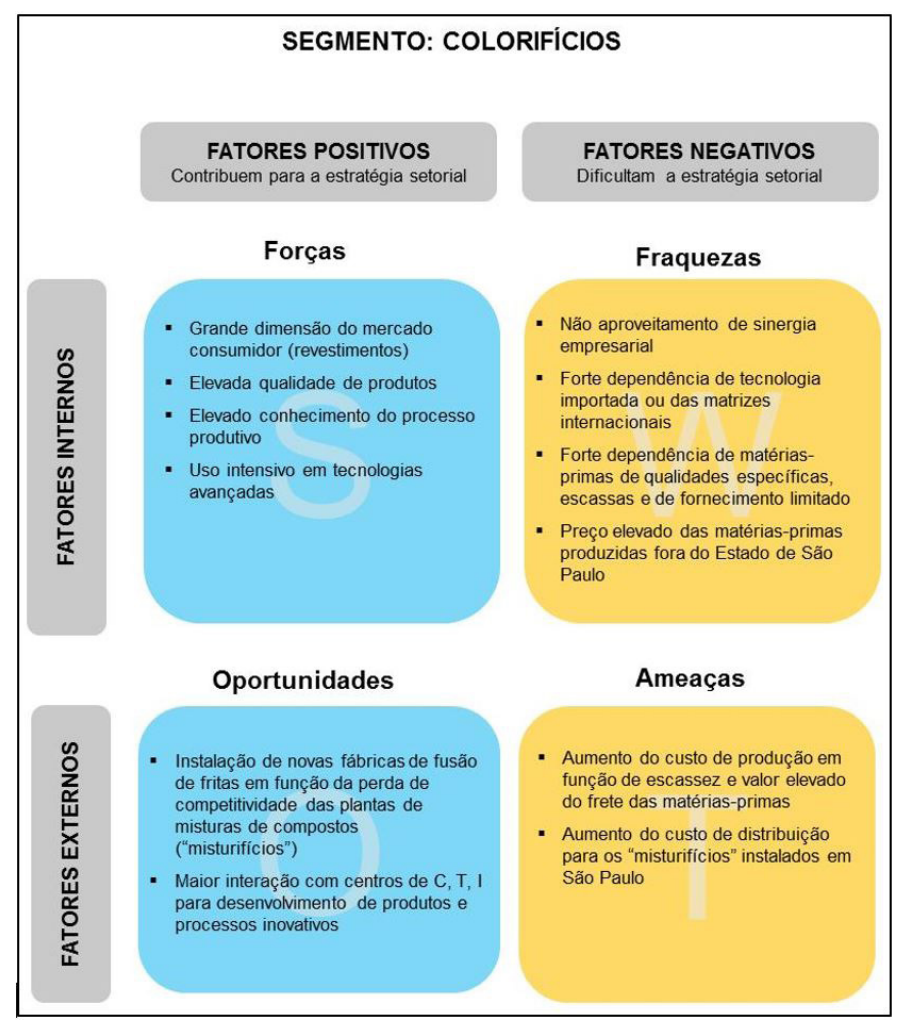

Figura 9 - Análise estratégica do segmento de Colorifícios no estado de São Paulo.

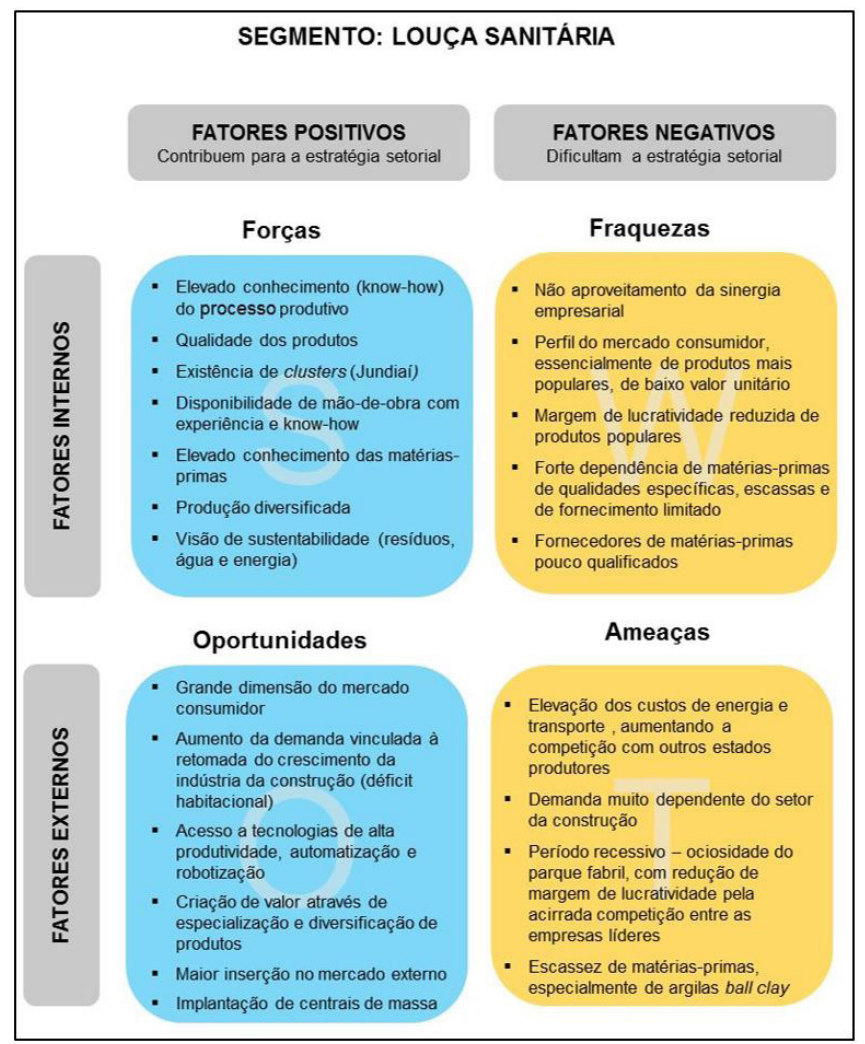

Figura 10 - Análise estratégica do segmento de Louça Sanitária no estado de São Paulo. 


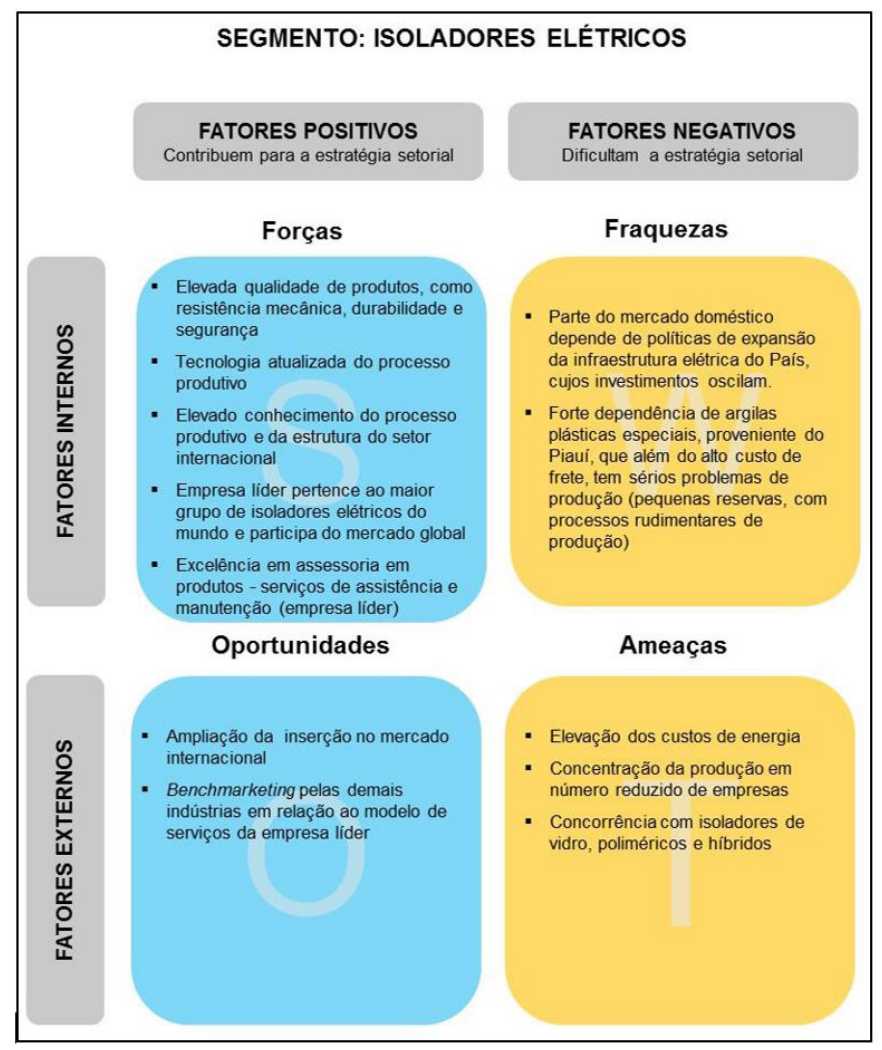

Figura 11 - Análise estratégica do segmento de Isoladores Elétricos no estado de São Paulo.

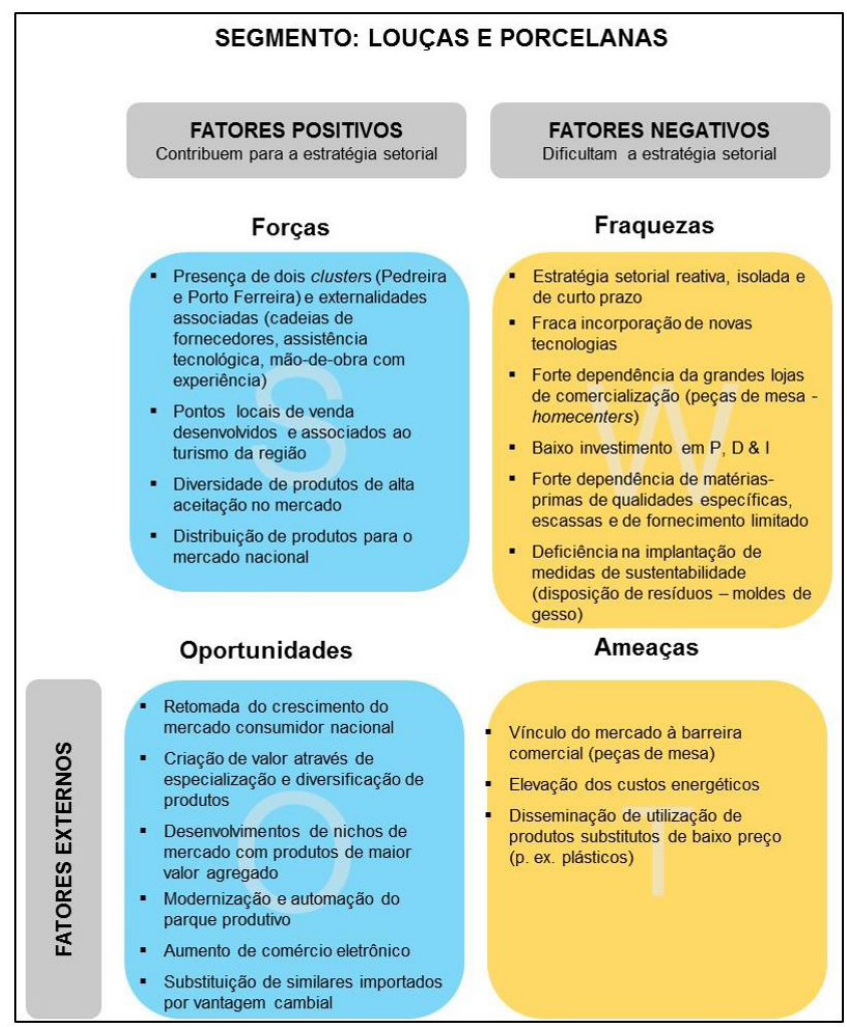

Figura 12 - Análise estratégica do segmento de Louças e Porcelana de Mesa e Decorativa no Estado de São Paulo. 
e) Estimular estudos de desenvolvimento tecnológico de depósitos, com o incremento de práticas de caracterização tecnológica e de beneficiamento, no sentido de propiciar um melhor conhecimento do desempenho funcional dos minerais industriais, garantindo melhor desempenho na indústria e maior agregação de valor aos produtos minerais das jazidas.

f) Fomentar a implantação de mineradoras comuns nos APLs mínero-cerâmicos como alternativa para solucionar a produção em maior escala de matéria-prima (argilas para cerâmica vermelha), com melhor controle de qualidade e facilitar a regularização das jazidas. Podendo ser gerida por cooperativa de mineradores e ceramistas, uma condução da mineração em melhores bases profissional e tecnológica deve propiciar ganhos econômicos (melhor aproveitamento das jazidas, menores custos de produção e diminuição de perdas no processo cerâmico) e ambientais (minimização de impactos pelo maior controle das operações de lavra e beneficiamento, e diminuição da proliferação caótica de cavas). A regularização dos empreendimentos é facilitada pela diminuição de minas e pela partilha dos custos envolvidos.

g) Estimular a implantação de centrais de massa. Enquanto as mineradoras ofertam simplesmente diferentes tipos de matérias-primas, as centrais avançam nas etapas de preparação de misturas balanceadas para os diferentes processos e produtos cerâmicos. Entre os benefícios estão a melhoria e maior controle da qualidade das matérias-primas e a possibilidade de simplificação e especialização das plantas industriais das cerâmicas, visto que algumas das etapas de preparação de massa, que tradicionalmente são feitas dentro das próprias cerâmicas, passariam a ser assumidas pelas centrais. Essas unidades podem estar acopladas à mineração ou constituírem empreendimentos isolados que processam matérias-primas de diferentes minas. Desse modo, podem se consolidar como elo especializado dentro da cadeia produtiva mínero-cerâmica.

\section{AGRADECIMENTOS}

Os autores expressam seus agradecimentos ao Instituto de Pesquisas Tecnológicas do Estado de São Paulo e a Subsecretaria de Mineração da Secretaria de Energia e Mineração - SEM do Estado de São Paulo (atualmente integrada às funções da Secretaria Estadual de Infraestrutura e Meio Ambiente - SIMA) pelo suporte e financiamento do projeto "Estudo estratégico da cadeia produtiva da indústria cerâmica no Estado de São Paulo - Fase 1", que gerou os resultados apresentados neste artigo.

\section{REFERÊNCIAS}

BELLINGIERI, J. C. A indústria cerâmica em São Paulo e a "invenção" do filtro de água: um estudo sobre a Cerâmica Lamparelli - Jaboticabal 1920-1947. In: CONGRESSO BRASILEIRO DE HISTÓRIA ECONÔMICA, 5., CONFERÊNCIA INTERNACIONAL DE HISTÓRIA DE EMPRESAS, 6., 2003, Caxambu. Atas... Belo Horizonte: ABPHE, 2003. $25 \mathrm{p}$.

CABRAL JUNIOR, M.; GAMBA, T. de C. Ordenamento Territorial Geomineiro (OTGM) do polo mínero-cerâmico de Santa Gertrudes - SP: um instrumento de planejamento e gestão para garantir do suprimento sustentável de recursos minerais. Revista de Gestão Ambiental e Sustentabilidade, v. 6, p. 54-73, 2017.

CABRAL JUNIOR, M.; AZEVEDO, P. B. M. de; CUCHIERATO, G.; MOTTA, J. F. M. Estudo Estratégico da Cadeia Produtiva da Indústria Cerâmica no Estado de São Paulo: Parte I Introdução e a Indústria de Cerâmica Vermelha. Cerâmica Industrial, v. 24, n. 1, p. 20 - 34, 2019a.

CABRAL JUNIOR, MARSIS; AZEVEDO, PAULO BRITO MOREIRA DE ; CUCHIERATO, GLÁUCIA ; MOTTA, JOSÉ FRANCISCO MARCIANO . Estudo Estratégico da Cadeia Produtiva da Indústria Cerâmica no Estado de São Paulo: Parte II Indústria de Revestimentos. Cerâmica Industrial, v. 24, n.2, p. 13-21, 2019b.

CABRAL JUNIOR, M.; AZEVEDO, P. B. M.; CUCHIERATO, G.; MOTTA, J. F. M. Estudo Estratégico da Cadeia Produtiva da Indústria Cerâmica no Estado de São Paulo: Parte III: Indústrias de Colorifícios, Sanitários e Cerâmica Técnica Isoladores. Cerâmica Industrial, v. 24, n. 3, p. 15-24, 2019c.

IPT - INSTITUTO DE PESQUISAS TECNOLÓGICAS DO ESTADO DE SÃO PAULO. Bases técnicas para modernização e consolidação do arranjo produtivo de cerâmica branca de Pedreira. São Paulo: IPT, 2006. (Rel. n. 90 869-205).

IPT - INSTITUTO DE PESQUISAS TECNOLÓGICAS DO ESTADO DE SÃO PAULO. Estudo estratégico da cadeia produtiva da indústria cerâmica no Estado de São Paulo - Fase 1. São Paulo: IPT, 2018. (Rel. n. 153900-205).

MDIC - MINISTÉRIO DA INDÚSTRIA, COMÉRCIO EXTERIOR E SERVIÇOS. Exportação e Importação Geral. Disponível em: <http:// http://comexstat.mdic.gov. br/en/geral $>$. Acesso em: 31 de jul. 2018.

RUIZ, M. S.; TANNO, L. C.; CABRAL JUNIOR, M.; COELHO, J. M.; NIEDZIELSKI, J. C. A Indústria de Louça e Porcelana de Mesa no Brasil. Cerâmica Industrial, v. 16, p. 29-34, 2011.

SÃO PAULO. Secretaria de Estado da Fazenda. (1992). Cerâmica: manual de conhecimentos. São Paulo. 57p. 